\title{
Influence of remineralisation and different ways of degradation on PCBs concentrations in coastal seas
}

\author{
ElEnA MiKheEVA ${ }^{1}$, JOHANNES BIESER ${ }^{2}$, CORINNA SCHRUM ${ }^{3}$ \\ ${ }^{1}$ Helmholtz-Zentrum Geesthacht, Institute of Coastal Research, \\ Max-Planck-Str. 1, 21502 Geesthacht, Germany \\ (elena.mikheeva@hzg.de) \\ ${ }^{2}$ Helmholtz-Zentrum Geesthacht, Institute of Coastal Research, \\ Max-Planck-Str. 1, 21502 Geesthacht, Germany \\ (johannes.bieser@hzg.de) \\ ${ }^{3}$ Helmholtz-Zentrum Geesthacht, Institute of Coastal Research, \\ Max-Planck-Str. 1, 21502 Geesthacht, Germany \\ (corinna.schrum@hzg.de)
}

Persistent organic pollutants (POPs) have a long residence time in the marine environment and can be subject to long-range transport (LRT). However, in the particular case of polychlorinated biphenyls (PCBs), these contaminants are quite hydrophobic and have a high tendency to accumulate on organic carbon, both living (plankton, fishes etc.) and dead (dissolved organic carbon, detritus). Due to processes of biomagnification in food chains, their presence in aquatic matrices is especially harmful for living organisms (incl. humans). Therefore, the detailed understanding of PCBs transformations is a key for estimating their concentration, particularly in coastal areas with high primary production.

In the current study, a numerical model has been developed to estimate the environmental fate of PCBs in the coastal marine ecosystem. For this, a Framework for Aquatic Biogeochemical Models (FABM) has been implemented into a high-resolution numerical hydrodynamic biogeochemical model.

We implemented the main degradation pathways, which are photolysis and biological degradation. The degradation of PCBs mainly depends on UV-light intensity in the surface ocean, the amount of other photon-absorbing compounds, temperature and food sources for bacteria. In current simulations these paths have been implemented separately, that allows to estimate the contribution of each of them.

Finally, sorption phenomena of PCBs on organic matter (dissolved (DOM) and particulate (POM)) are quite intensive and leave not much freely dissolved pollutants. However, due to processes such as remineralisation, sorbed PCBs can be returned back to a dissolved phase. In this form, contaminants have a higher potential for uptake by living organisms. Moreover, transformation between dissolved and particulate phases determine the transport of PCBs in the water column leading to different sinks (e.g. sediments, biota, LRT) in different regions.

Here we present first simulations of the fate of PCBs in European coastal seas. 